\title{
Moldagem superplástica em liga de titânio
}

\author{
Superplastic moulding of titanium alloy
}

Augusto Eduardo B. Antunes ${ }^{1}$, Lídia M. D. Antunes ${ }^{2}$

\begin{abstract}
Resumo
A moldagem superplástica consiste na estampagem de chapas metálicas em alta temperatura, por intermédio de gás sob pressão. Neste trabalho, apresenta-se o desenvolvimento do projeto para a aplicação desta técnica, visando obter peças com a liga de titânio do tipo Ti-6Al-4V. Os equipamentos e acessórios empregados foram integralmente projetados e construídos para a finalidade, e ao longo das atividades tiveram constantes aperfeiçoamentos. Os resultados obtidos permitem concluir que a execução deste processo de moldagem não apresenta dificuldades. Entretanto, dependendo do tamanho e complexidade da peça a ser confeccionada, o conjunto de equipamentos e métodos necessários dependem de técnicas bem elaboradas e controladas. As peças obtidas apresentaram um bom acabamento e a possibilidade de uma boa precisão dimensional. Um resultado significativo do projeto consiste na experiência adquirida na sua elaboração. Em vista disto, o trabalho descreve os principais detalhes técnicos empregados, entre os quais, as vantagens de se moldar peças sucessivamente, de modo a economizar energia e tempo de moldagem e assim, aumentar o potencial aplicativo do processo para diferentes segmentos industriais.
\end{abstract}

Palavras-chave: Conformação Superplástica; Superplasticidade; Moldagem; Liga de titânio.

\begin{abstract}
Superplastic moulding involves the shaping of metals sheets by gas pressure at elevated temperatures. This paper reports on investigations related to application of this forming technics, in getting pieces with titanium alloy of the type Ti-6Al-4V. The results show that the moulding process presents no difficulties. But, the whole set of the accessories and the artifice to get good performance of the process involve technics that must be well controlled and improved, depending on the size or complexity of the piece worked. The equipments and devices to prepare the experiments were particularly designed and constructed to the purpose, and suffered constantly modifications to attend improvements and propitiate versatility and producibility during the course of the activities. The gotten pieces showed a good finishing and possibility of a good dimensional precision. The much more interesting results of the experiment was the experience obtained during the development of the process and so, we intend to present its many stages, technical characteristics and the potencial application in differents industrials segments.
\end{abstract}

Keywords: Superplastic Forming; Superplasticity; Moulding; Titanium alloy.

\footnotetext{
"Universidade Estadual Paulista "Júlio de Mesquita Filho" (UNESP) - Guaratinguetá/SP - Brasil

${ }^{2}$ Instituto de Estudos Avançados - São José dos Campos/SP - Brasil

Autor correspondente: Lídia M. D. Antunes - E-mail: lidia.dantunes@gmail.com
} 


\section{Introdução}

O fenômeno da superplasticidade é caracterizado pela grande deformação que alguns materiais apresentam quando submetidos a tensões numa temperatura e taxa de deformação apropriadas, produzindo alongamentos de 300 a $3000 \%{ }^{(1)}$. Portanto, muito maior do que as deformações que ocorrem normalmente com os metais, que dificilmente atingem um alongamento de $50 \%$. Na superplasticidade, também ocorre substancial redução no nível das tensões necessárias à deformação, da ordem de duzentas vezes menor. Resulta então, que por conformação superplástica pode-se fabricar peças com maior deformação plástica e muito menor nível de esforço que os necessários aos processos usuais de conformação. $\mathrm{O}$ fenômeno é conhecido desde antes da II Guerra Mundial ${ }^{(2)}$, a partir de então tem sido avaliado em um grande número de ligas e metais puros ${ }^{(3)}$.

O fenômeno da superplasticidade tem sido observado em algumas ligas quando a deformação ocorre em temperatura superior a $40 \%$ da temperatura absoluta de fusão da liga e numa situação onde a tensão de deformação torna-se muito sensível à taxa de deformação. Este efeito pode ser avaliado pelo expoente de sensibilidade da tensão à taxa de deformação $m$, na expressão $\sigma=k \varepsilon^{m}$. Na qual $\sigma$ é a tensão necessária para a deformação, $k$ uma constante e $\dot{\varepsilon}$ a taxa de deformação. $\mathrm{O}$ expoente $m$ pode ser avaliado por:

$$
m=\frac{d \log \sigma}{d \log \dot{s}}
$$

que é um parâmetro que indica a resistência do material à instabilidade plástica local (estricção) que conduz à ruptura ${ }^{(4)}$.

O comportamento superplástico é observado quando os valores de $m$ são maiores que 0,3 . O requisito metalúrgico básico para a liga apresentar o fenômeno da superplasticidade é possuir tamanho de grão pequeno, menor que $10 \mu \mathrm{m}$ e que este se altere pouco na temperatura de deformação. Devido as características microestruturais necessárias, o fenômeno não ocorre em todas as ligas, e ainda assim, normalmente, as ligas superplásticas necessitam ser submetidas a processamento termomecânico conveniente. Com facilidades nesse sentido, destaca-se a liga Ti-6Al-4V, que por apresentar grande resistência mecânica e relativa baixa densidade, componentes aeronáuticos tem sido fabricados por intermédio da conformação superplástica ${ }^{(5)}$.

A conformação de ligas superplásticas requer métodos e equipamentos que assemelham-se mais aos usados na conformação de materiais poliméricos termoplásticos do que aqueles empregados na conformação convencional de metais. Relativo a conformação de chapas, os métodos de estampagem recaem usualmente em dois procedimentos: estampagem "a sopro" e a estampagem por "ferramenta móvel". Em decorrência do baixo nível de tensão necessário à deformação superplástica, os processos por sopro são eficientes e os mais empregados. Neste caso, a chapa a ser trabalhada é fixada no molde por uma tampa e após aquecimento até a temperatura superplástica, o gás é injetado entre a tampa e a chapa para que esta adquira a forma do molde. $\mathrm{O}$ gás pode ser o ar se não acarretar oxidação ou contaminação da liga na temperatura de moldagem. Para materiais reativos, caso das ligas de titânio, deve ser empregado gás inerte, como o argônio.

Assim, é intuito deste trabalho apresentar atividades relacionadas à aplicação da técnica da moldagem superplástica direcionada à estampagem de chapas da liga Ti-6Al-4V. Adicionalmente, em sentido mais amplo, além do desenvolvimento técnico, pretendeu-se adquirir experiência e discernimento crítico quanto ao potencial de utilização do processo, visando adequá-lo para outras ligas superplásticas, avaliar a possibilidade de efetuar moldagens consecutivas, de forma a aumentar a produtividade do processo e assim expandir seu campo de utilização para diferentes aplicações industriais.

\section{Material e Métodos}

Experimentos foram efetuados com a liga $T \mathrm{i}-6 \mathrm{Al}-4 \mathrm{~V}$, na forma de chapa com $0,7 \mathrm{~mm}$ de espessura. Esta liga é bifásica (grãos a de estrutura hexagonal compacta e grãos b de estrutura cúbica de corpo centrado) com grãos equiaxiais da ordem de $8 \mu \mathrm{m}$ de diâmetro. As chapas foram utilizadas na condição como adquiridas, sem nenhum reprocessamento termomecânico. Segundo a literatura, o fenômeno da superplasticidade nesta liga ocorre em temperaturas de 900 a $950^{\circ} \mathrm{C}$ numa taxa de deformação da ordem de $2 \times 10^{-4} \mathrm{~s}^{-1}{ }^{(6,7)}$. A composição química da liga de titânio empregada nos experimentos é apresentada na Tabela 1. Suas propriedades mecânicas na condição de aquisição, laminada a quente e seguida de recozimento na temperatura de $800^{\circ} \mathrm{C}$ por duas horas, estão indicadas na Tabela 2. 
Tabela 1. Composição química da liga de titânio.

\begin{tabular}{c|c|c|c|c|c|c|c|} 
Elemento & $\mathrm{Al}$ & $\mathrm{V}$ & $\mathrm{Fe}$ & $\mathrm{O}$ & $\mathrm{C}$ & $\mathrm{N}$ & $\mathrm{H}$ \\
\hline \% peso & 6,20 & 4,10 & 0,30 & 0,20 & 0,06 & 0,05 & 0,15
\end{tabular}

Tabela 2. Propriedades mecânicas da liga de titânio

\begin{tabular}{c|c|c}
$\begin{array}{c}\text { Limite de Resistência } \\
\text { a Tração [MPa] }\end{array}$ & $\begin{array}{c}\text { Limite de } \\
\text { Escoamento } \\
\text { [MPa] }\end{array}$ & $\begin{array}{c}\text { Alongamento } \\
\%\end{array}$ \\
\hline 960 & 880 & 8,5 \\
\hline
\end{tabular}

O trabalho caracteriza-se por uma constante evolução dos procedimentos técnicos e todos os equipamentos e acessórios empregados foram integralmente projetados e construídos para a finalidade, e ao longo do desenvolvimento sofreram constantes aperfeiçoamentos. Nos estágios iniciais, moldagens simplificadas foram efetuadas de forma a propiciar discernimentos sobre os aspectos básicos do processo. Assim, avaliou-se a moldagem de pequenas calotas esféricas, na qual, o molde com a chapa em seu interior era tampado e hermeticamente lacrado com parafusos. Após a prévia introdução de argônio nas cavidades internas do molde para remoção do ar, o conjunto era colocado em um forno de mufla previamente aquecido na temperatura de $700^{\circ} \mathrm{C}$. Em seguida, o forno era reaquecido para a temperatura de conformação, da ordem de $900^{\circ} \mathrm{C}$. A moldagem superplástica foi obtida com diferentes períodos de permanência no forno, até por 2 horas. As pressões de argônio empregadas chegaram a atingir $10 \mathrm{~atm}$. Após a moldagem, o conjunto era retirado do forno e esfriado para a temperatura ambiente, quando finalmente era aberta a tampa e retirada a peça estampada. Apesar da simplicidade destes experimentos iniciais, foi possível detectar as principais dificuldades técnicas e operacionais do processo. Os problemas mais notórios decorreram da operação em alta temperatura, que produz vazamentos de argônio na junção entre o molde e a tampa e muita oxidação nas partes externas do molde. Além disso, a necessidade de aquecimento e resfriamento do molde torna lento o ciclo do processo e causa trincas no molde e na tampa, após a produção de poucas peças. Mesmo assim, foi possível perceber que, os problemas poderiam ser evitados pela introdução de novas técnicas e procedimentos operacionais mais adequados. Este foi o objetivo do presente trabalho. Nesse sentido, um aspecto significativo seria a otimização do ciclo de moldagem, para diminuir o tempo de fabricação e também a possibilidade de obtenção de peças sucessivas, tornando o processo mais atraente para a produção industrial. Neste caso, o molde deve permanecer sempre aquecido e as chapas sequecialmente estampadas. Para isto, a tampa do molde deve ser aberta em alta temperatura e a chapa introduzida sem seu interior, seguindo-se com o fechamento do sistema. Após a moldagem, o conjunto é reaberto, retira-se a peça estampada e introduz-se uma nova chapa, repetindo-se o ciclo. Em todas as operações, as partes do sistema, a chapa e a peça, devem ser protegidas com argônio contra a oxidação atmosférica em alta temperatura.

No projeto optou-se por um forno do "tipo poço" operando segundo o esquema da Fig. 1. Da forma como ilustrado, quando a tampa do molde é levantada traz consigo a tampa do forno. Em seguida é introduzida a chapa, estando o molde na temperatura de conformação. Segue imediato fechamento do conjunto molde e forno. Apesar da constante purgagem com argônio no interior do molde e do forno para diminuir a possibilidade de oxidação, principalmente da chapa e do interior do molde, esta operação é conduzida rapidamente, num tempo da ordem de 15 segundos. Devido a rapidez da movimentação na abertura e fechamento das tampas, sem a necessidade de grandes esforços, optou-se por um atuador pneumático. Uma vez introduzida a chapa e recolocadas as tampas, é efetuado uma précarga com um atuador hidráulico, sobre a tampa do molde, para acomodar e moldar a vedação na borda da chapa, da forma como esquematizado na Fig. 2. Em seguida, ainda sob a ação do atuador hidráulico, exerce-se a carga para garantir a hermeticidade da vedação e manter o fechamento, contrapondo em cinco vezes a força exercida pela pressão do gás de moldagem que atua sob a tampa no sentido de abri-la. Após a conformação, as tampas são levantadas e a peça moldada é retirada para dentro de uma câmara com atmosfera de argônio colocada próximo a borda do forno. A peça

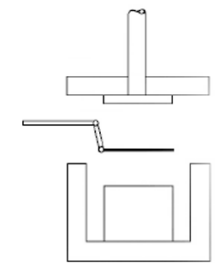

a

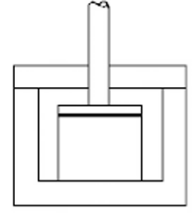

b

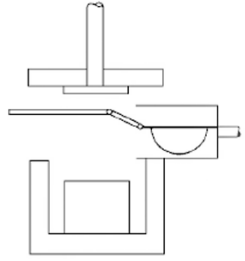

C
Figura 1. Esquema operacional do sistema de moldagem, (a) colocação, (b) fechamento, (c) retirada. 
esfria para a temperatura ambiente dentro desta câmara. $\mathrm{O}$ ciclo para a moldagem de uma peça é exemplificado pelo esquema apresentado na Fig. 3.

A Fig. 4 apresenta o sistema projetado e construído para elaborar os experimentos. Na parte central encontra-se o forno com o sistema de movimentação e vedação das tampas do molde e do forno. À esquerda, encontra-se o módulo de comando dos atuadores pneumático e

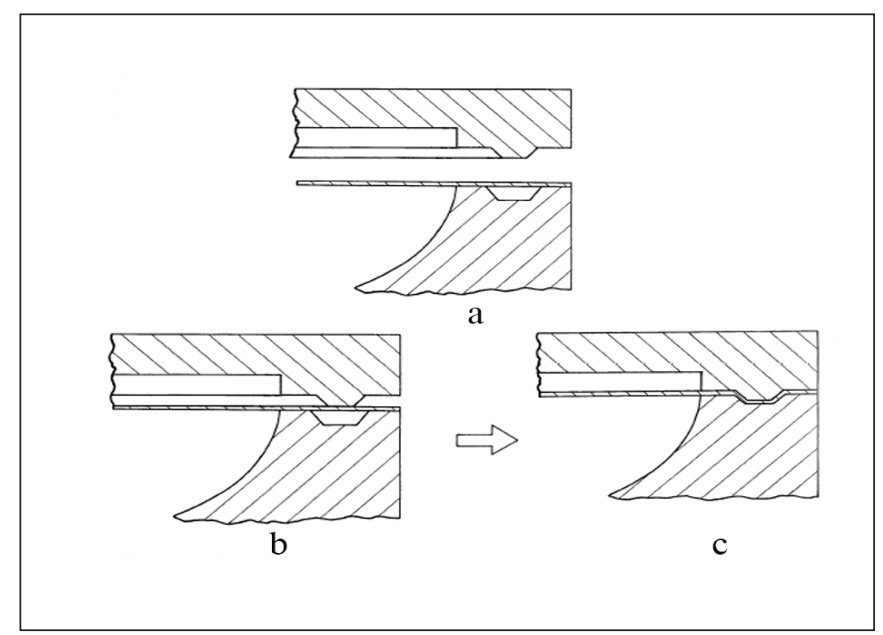

Figura 2. Moldagem da vedação, (a) colocação, (b) fechamento, (c) precarga. hidráulico. À direita encontra-se o comando do forno e dos gases para moldagem e proteção. A Fig. 5 mostra o molde aberto no interior do forno. A tampa do molde é movimentada e sustentada por uma haste tubular onde pelo seu interior passam tubos que conduzem argônio para moldagem e purgagem. O forno com $8000 \mathrm{~W}$ é aquecido com resistências elétricas posicionadas nas reentrâncias do refratário. Um esquema ilustrando as

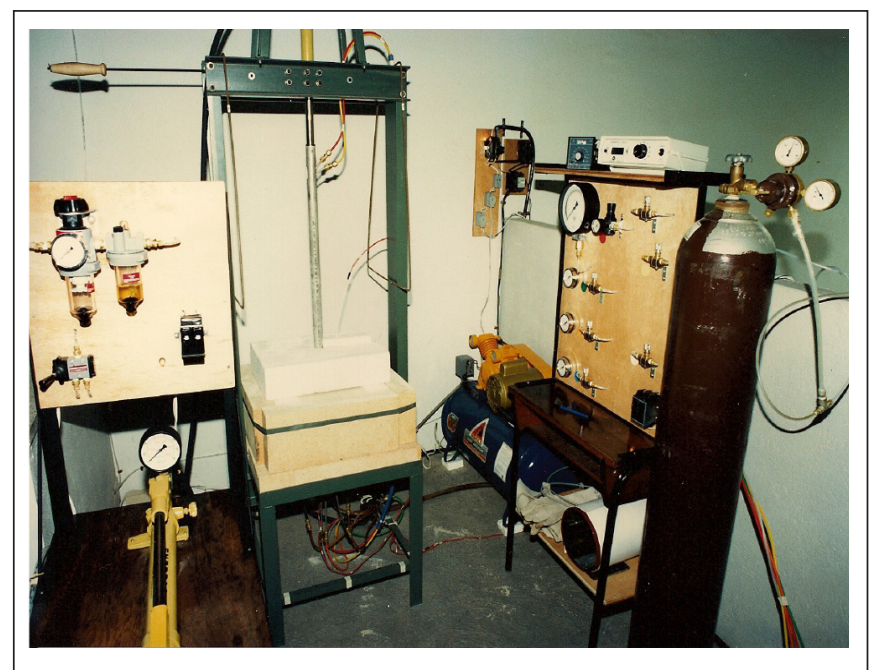

Figura 4. Sistema empregado nos experimentos.

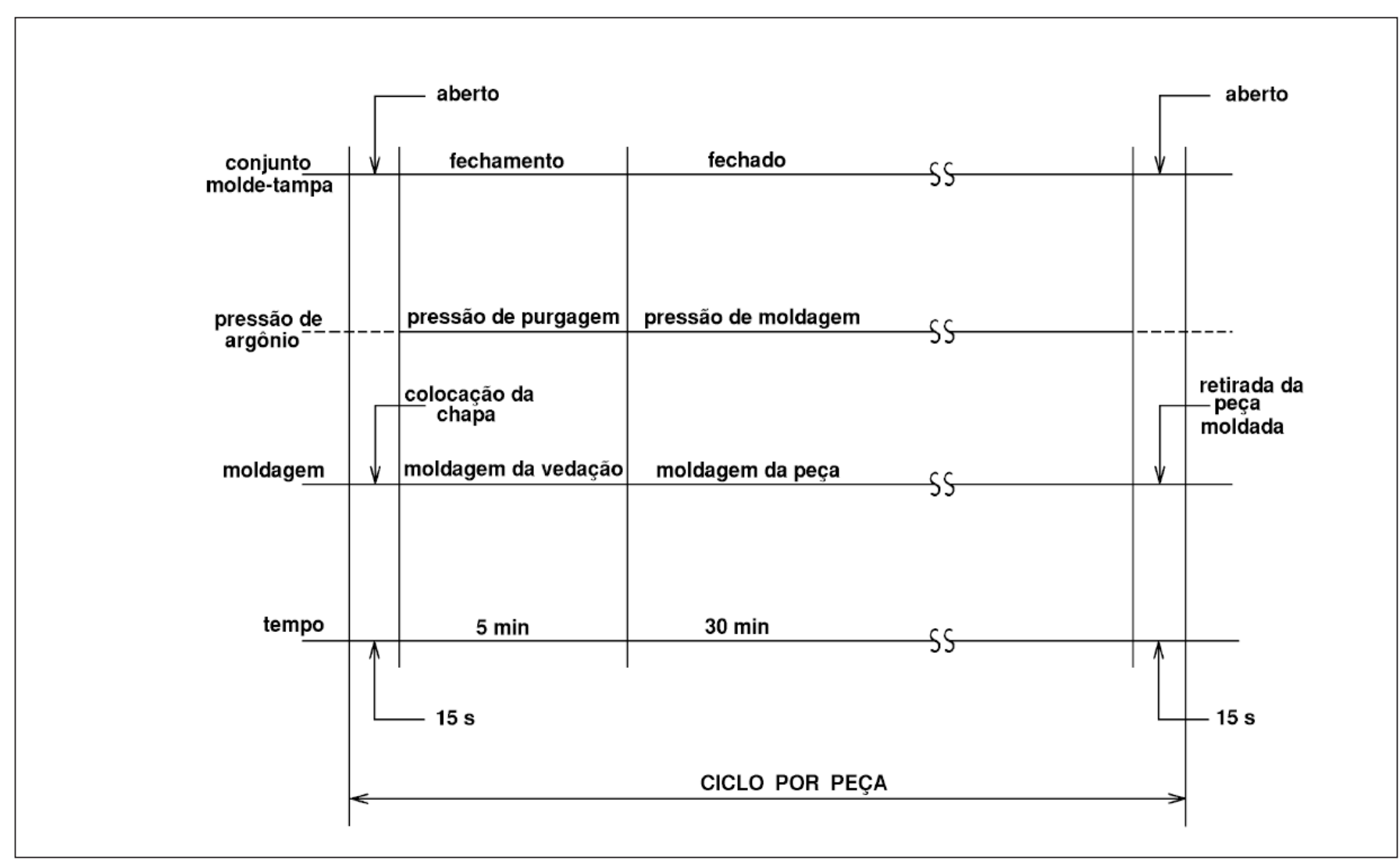

Figura 3. Ciclo da moldagem superplástica. 
principais partes do sistema de moldagem empregado no trabalho consta na Fig. 6. Na Fig. 7 é mostrada uma calota em liga de titânio, com $120 \mu \mathrm{m}$ de diâmetro, moldada superplasticamente com os dispositivos desenvolvidos no trabalho.

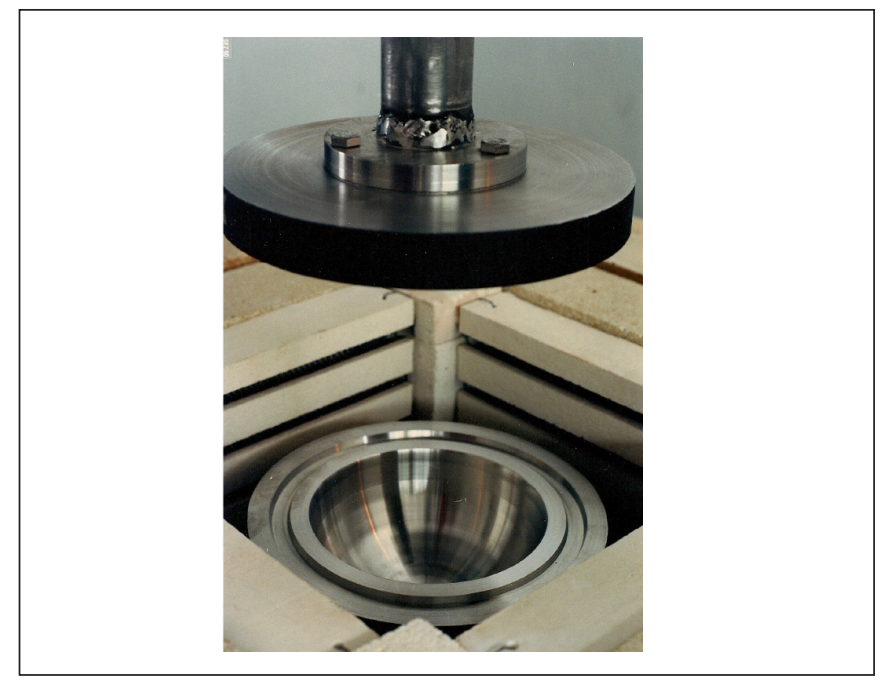

Figura 5. Forno com o molde aberto em seu interior.

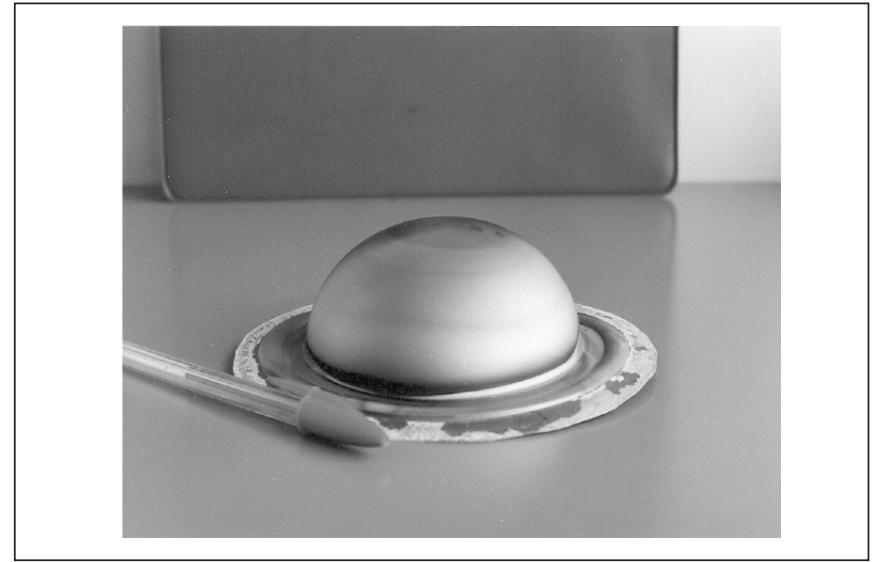

Figura 7. Peça em liga de titânio moldada superplasticamente.

\section{Resultados}

Os experimentos demonstram a viabilidade do emprego do processo para fabricação de peças industriais em ligas superplásticas, indicando que objetivos almejados podem

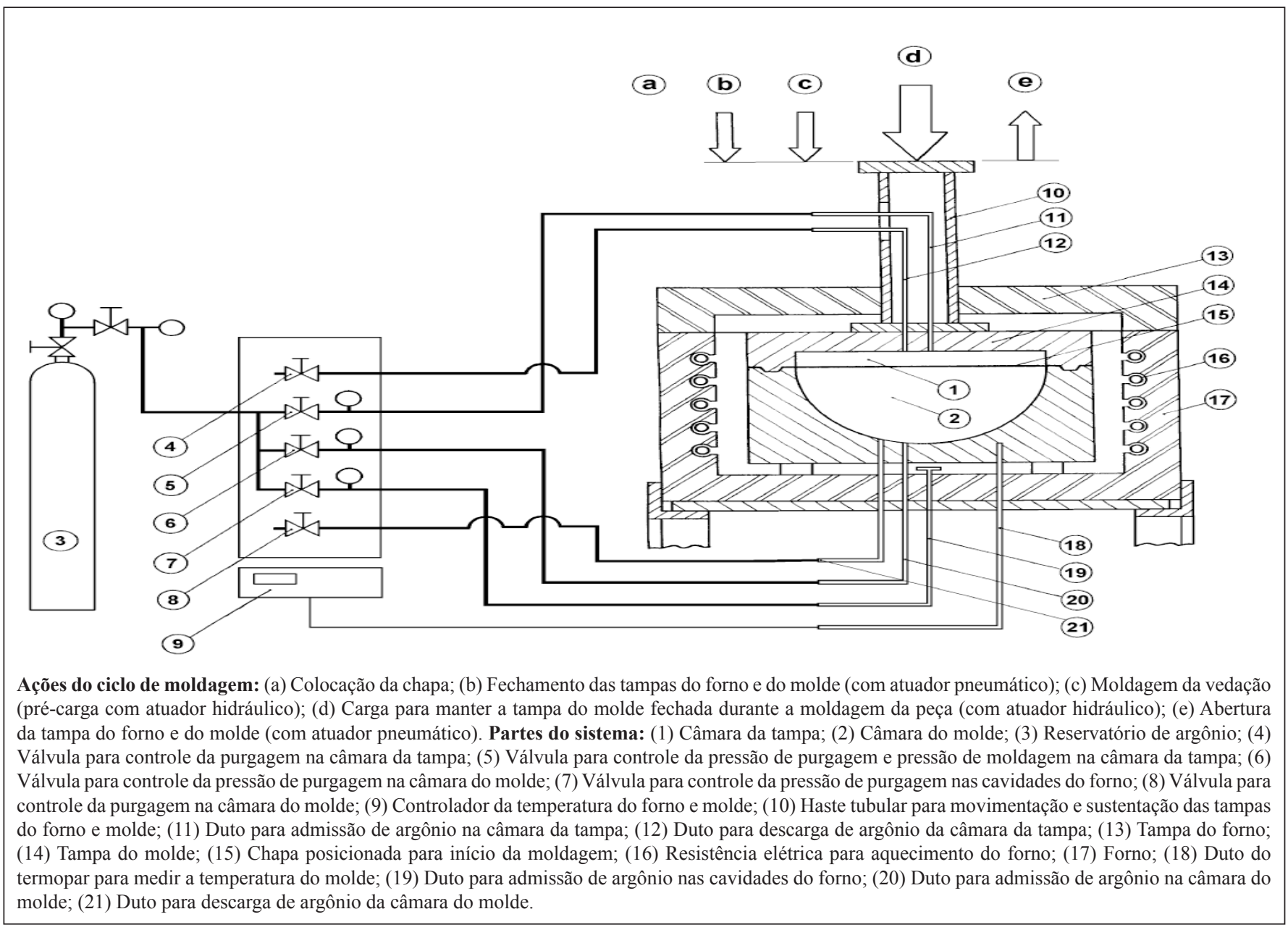

Figura 6. Esquema do sistema de moldagem superplástica. 
ser alcançados sem dificuldades com o desenvolvimento de técnicas adequadas. Foi possível introduzir chapas dentro do molde aquecido, tampa-lo de forma hermética e retirar seguidamente peças estampadas em alta temperatura, simulando uma produção industrial. Apesar da reatividade do titânio ao ar na temperatura de moldagem, as superfícies das peças apresentaram reduzida oxidação, como se verifica na Fig. 7. A ocorrência de manchas em regiões localizadas das peças estão associadas aos locais de injeção e saída de gases no molde. Entretanto, este problema pode ser contornado com a utilização de argônio mais puro e principalmente com um melhor controle da técnica da purgagem em todo o sistema. A moldagem com a liga Ti-6Al-4V sob condições superplásticas apresenta resultados satisfatórios sem dificuldades, mesmo levando-se em consideração que as conformações realizadas foram conduzidos sem avaliação precisa das características superplásticas da liga empregada. Conforme já mencionado, os parâmetros superplásticos usados nos experimentos foram obtidos da literatura, ou seja, são valores genéricos para esta classe de liga, independentes de suas condições metalúrgicas. Apesar das operações de moldagem terem sido, provavelmente, conduzidas fora dos parâmetros superplásticos ideais para a liga empregada no trabalho, gradativamente as peças obtidas apresentaram melhores características, com superfície sem rugosidade ou irregularidade. Em conseqüência disto, mesmo ponderando o pequeno tamanho e simplicidade geométrica das peças produzidas, admite-se que, sem maiores dificuldades técnicas, peças mais complexas de maior ou menor porte poderão ser também fabricadas.

\section{Discussão}

Na conformação superplástica é importante a seleção do material para confecção dos moldes, quando destinados à moldagem de ligas que requerem temperaturas superplásticas elevadas devem ser escolhidos materiais refratários (ligas metálicas ou cerâmicas). Mesmo assim, para maior durabilidade dos moldes, durante as operações de conformação é conveniente evitar choques térmicos e também protege-lo contra a oxidação em alta temperatura quando o mesmo for metálico. Choques térmicos foram evitados nos experimentos, tendo em vista que os ciclos mantiveram a temperatura do molde aproximadamente constante, apesar da pequena perda de calor no momento de retirada da peça moldada e a colocação de uma nova chapa. Em função disto, não foram observadas trincas por fadiga térmica nos moldes. Por motivo econômico, os moldes foram confeccionados com aço inoxidável austenítico do tipo 304, que não é recomendado para resistir a oxidação nas temperaturas em que foram empregados. Como consequência, formou-se densa carepa de oxidação em sua parte externa, devido a insuficiente introdução de argônio nas cavidades do forno. Entretanto, esta oxidação não prejudicou as sucessivas operações de moldagem realizadas. Um aspecto significativo, é que nas câmaras da tampa e do molde, onde a proteção de argônio foi eficiente, as superfícies permaneceram intactas, sem qualquer indício de oxidação. Sendo assim, significa, que a proteção com argônio foi atuante no período de abertura e fechamento da tampa do molde.

Apesar da facilidade da moldagem superplástica relativo aos demais processos convencionais de estampagem, sua utilização também apresenta desvantagens:

- Não é possível emprega-la em todas as ligas de interesse industrial;

- A moldagem necessita de temperaturas elevadas;

- A produtividade é pequena, devido a baixa taxa de deformação na qual a superplasticidade manifesta-se.

Contudo, conhecimentos recentes sobre o fenômeno, fornecem subsídios para expandir a aplicabilidade do processo. Assim, tem sido avaliado que, ligas com tamanho de grão ultrafino, da ordem de $0,5 \mu \mathrm{m}$, podem tornar-se superplásticas ${ }^{(8)}$. Tamanho de grão dez vezes menores em ligas de titânio superplásticas, permitem uma diminuição de $200^{\circ} \mathrm{C}$ na temperatura de deformação superplástica ${ }^{(9)}$. Por outro lado, quando ligas com tamanho de grão ultrafino são suficientemente estáveis em altas temperaturas, nas quais os processos de difusão são rápidos, é possível efetuar a moldagem superplástica com taxa de deformação mais elevada, ou seja, num menor tempo ${ }^{(10)}$. A taxa de deformação deve ser selecionada para produzir as condições mais adequadas para a moldagem da peça. Entretanto, tem sido também avaliado que, exercendo-se uma alta taxa de deformação no início da moldagem e gradativamente reduzindo-a, conforme a peça é deformada, pode-se moldar peças num período de tempo menor. Empregando esta técnica em ligas de titânio superplásticas, para uma deformação de $100 \%$, foi possível reduzir o tempo de moldagem de 55 para 9 minutos $^{(11)}$. Em função dos aspectos mencionados, o desenvolvimento de tratamentos termomecânicos para diminuir o tamanho de 
grão das ligas é um grande atrativo para contornar as desvantagens da moldagem superplástica ${ }^{(12,13)}$. Desta forma, por este artifício metalúrgico, pode-se viabilizar o processo para vários tipos de ligas, diminuir a temperatura e o tempo de moldagem. Isto tem motivado novos interesses na aplicação da moldagem superplástica para a obtenção de peças, principalmente em ligas de alumínio e de titânio para a industria aeroespacial e de veículos automotivos.

Por outro lado, os experimentos realizados demonstram que a moldagem da liga Ti-6Al-4V não apresenta dificuldades, apesar da reatividade da liga com o oxigênio do ar na elevada temperatura necessária ao processo. Fica evidente, como pode ser constatado na Fig. 3, que a maior desvantagem é devida ao longo ciclo do processo, que é onerado pelo tempo de moldagem. Sendo assim, existe o interesse econômico para reduzir de todas as formas possíveis o ciclo de moldagem. Portanto, o trabalho indica ainda, que pode-se também contribuir para otimizar este ciclo, efetuando-se de forma eficiente a moldagem sucessiva das peças.

\section{Conclusão}

Com os experimentos elaborados, os principais procedimentos necessários a moldagem superplástica pela técnica de sopro puderam ser avaliados.

Baseados nos resultados obtidos, pode-se concluir que, a obtenção de peças com a liga Ti-6Al-4V por este processo não apresenta dificuldades técnicas. Em função

\section{Referências}

1. Hamilton, C.H., Superplastic forming makes molded parts from sheet metal alloys. Industrial Research \& Development, p. 72-76, December 1983.

2. Pearson, C.E., The viscous properties of extruded eutetic alloys of lead-tin and bismuth-tin. J. Inst. Metals, n. 54, p. 111-124, 1934.

3. Pagnano, C.A.G., Victoria, M.P., Deformação superplástica em metais puros e ligas. Metalurgia, ABM, v. 28, n. 173, p. 271-280, abril 1972.

4. Dieter, G.E., Mechanical Metallurgy. McGraw-Hill, 1976.

5. Serra, D., Superplastic Forming Applications on aero engines. A review of manufacturing process. In: EUROSPF CONFERENCE, 6, from 3-5 September 2008, Carcassonne, France. disto, admite-se que, também sem maiores dificuldades, podem ser moldadas peças com geometria mais complexa, de maior ou menor porte, utilizando-se diferentes ligas superplásticas.

Com o objetivo de economizar energia térmica, reduzir o tempo do ciclo de moldagem e proteger o molde contra a fadiga térmica, foi possível demonstrar a viabilidade de inserir chapas e retirar peças estampadas do interior do molde, que permanecia sempre aquecido, sem degradar as superfícies dos materiais. Apesar da liga de titânio utilizada apresentar uma grande taxa de oxidação ao ar na sua alta temperatura de moldagem.

Além do trabalho demonstrar que, procedimentos e técnicas bem elaboradas podem contribuir para diminuir o ciclo de moldagem; o desenvolvimento de tratamentos termomecânicos para produzir grãos ultrafinos tem viabilizado o processo para vários tipos de liga e diminuído o tempo e temperatura de moldagem. Assim, o arcabouço deste desenvolvimento motiva novas aplicações da moldagem superplástica na industria.

\section{Agradecimento}

Os autores agradecem a Paulo Sergio F. Valdez, Jorge Montané Vila e César Renato F. Ribeiro pela colaboração no desenvolvimento do trabalho. Agradecem a Secretaria de Ciência e Tecnologia do Estado de São Paulo pelo apoio financeiro.

6. Paton, N.E., Hamilton, C.H., Superplasticity in titanium alloys. In: Proceeding Of International Conference On Titanium, 5, Deutsche Gesellshaft Fuer Metallkunde E.V., v. 3, p. 649-672, 1984.

7. Ward, D.M., Superplastic forming of titanium alloys. Metals and Materials, p. 560-563, September 1986.

8. Ruslan, Z.V., Dmitri, A.S., Nikolai, K.T., Patrick, B.B., Terence, G.L., Observations of hight strain rate superplasticity in commercial aluminum alloys with ultrafine grain sizes. Scripta Materialia, v. 37, n. 12, p. 1945-1950, 1997.

9. Kaibjshev, O.A., Safiullin, R.V., Lutfullin, R.Y., Valiakhmetov, O.R., Galeyev, R.M., Dutta, A., Raghu, T., Saha, G.G., Advanced superplastic forming and diffusion bonding of titanium alloy. Materials Science and Technology, v. 22, n. 3, p. 343-348, 2006. 
10. Lee, S., Furukawa, M., Horita, Z., Langdon, T.G., Developing a superplastic forming capability in a commercial aluminum alloy without scandium or zirconium additions. Materials Science and Enginnering, A 342, p. 294-301, 2003.

11. Comley, P., Multi-rate superplastic forming of fine grain Ti-6Al-4V titanium alloy. Journal of Materials Engineering and Performance, v. 16, n. 2, p. 150-154, April 2007.
12. Komura, S., Horita, Z., Furukawa, M., Nemoto, M., Langdon, T.G., An evaluation of the flow behavior during high strain rate superplasticity in al $\mathrm{Al}-\mathrm{Mg}$-Sc alloy. Metallurgical and Materials Transactions, A, v. 32A, p. 707-716, 2001.

13. Lee, S., Berbon, P.B., Furukawa, M., Horita, Z., Nemoto, M., Tsenev, N.K., Valiev, R.Z., Langdon, T.G., Developing superplastic properties in a aluminum alloy through severe plastic deformation. Materials Science and Engineering, A 272, p. 63-72, 1999. 